\title{
Multi-functional Cotton Fabrics Using Nano-Technology and Environmentally Friendly Finishing Agents
}

\author{
A. Abou-Okeil*1, R. A. A. Eid ${ }^{2}$, A. Amr ${ }^{1}$ \\ ${ }^{1}$ Textile Research Division, National Research Centre, 33 Bohouth St., Dokki, Giza, \\ Egypt, P. O. 12622, Affiliation ID: $60014618^{2}$ Faculty of Home Economic, Menoufia \\ University-Egypt.
}

\begin{abstract}
$\mathbf{T}$ $\mathrm{io}_{2}$ NANOPARTICLES were prepared using sol-gel technique. The prepared nanoparticles were analyzed using transmission electron microscope (TEM). Cotton fabrics were treated using prepared $\mathrm{TiO}_{2}$ nanoparticles in presence of citric acid and commercially flame retarding agent named Flovan CWF to produce cotton fabrics having multi-functional properties (anticrease, self cleaning, and flame retardant) using pad-dry-cure- method. The treated fabrics examined by several testing and analysis methods such as crease recovery angle (CRA), tensile strength (TS), elongation at break (El), whiteness index (WI), self cleaning through $\mathrm{K} / \mathrm{S}$ measurement and flame retarding properties through thermogravimetric analysis (TGA). Results obtained reveal that the optimum condition for the preparation of multi-functional cotton fabric is by using the following formulation (6 \% citric acid, $3 \% \mathrm{TiO}_{2}, 300 \mathrm{~g} / 1$ Flovan $\mathrm{CWF}$ ) padded for pick-up $100 \%$, dried at $100^{\circ} \mathrm{C}$ for $5 \mathrm{~min}$ and cured at $160^{\circ} \mathrm{C}$ for $3 \mathrm{~min}$. The presence of $\mathrm{TiO}_{2}$ nanoparticles on the surface of the fabrics was proofed using EDX and the fabrics were examined also using scanning electron microscope.
\end{abstract}

Keywords: Multifunctional, cotton fabrics, $\mathrm{TiO}_{2}$, self cleaning, anti-crease, finishing, nanoparticles.

\section{Introduction}

Cotton fabrics are considered one of the most important textile fibres world wide, Cotton fabrics have many advantages over all other types of textile fibres. The serious defect of cotton fabrics is its ability to ignite easily. Many trials are conducted to impart flame retardant properties for cotton fabrics [1]. Halogens based organic compounds were used as a flame retarding agents for cotton fabrics, but due to the hazard effect of these compounds on health and environment, many countries restricted the use of these compounds [2]. Phosphorus based organic compounds were used as safe alternatives for halogen compounds. They are effective flame retardants for cotton fabrics [3]. Nowadays all flame retardant compounds are based on phosphorus organic compounds [4-8].

Nanotechnology was first used in textile industries in USA [9]. Nanoparticles can be applied on textile fabrics by coating on the surface of fabrics using several techniques such as spraying, printing and padding [10-12]. Textile fabrics can acquire many properties using nanotechnology including water repellence, soil resistance, wrinkle resistance, flame retardant, .........etc. The commonly used nanoparticles in textile industry are $\mathrm{Ag}, \mathrm{ZnO}, \mathrm{TiO}_{2}, \mathrm{CuO}$ and $\mathrm{Al}_{2} \mathrm{O}_{3}$ [13-15] .The aim of the present work is to impart multi-functional properties for cotton fabric such as flame retardance, self cleaning and anti-crease using environmentally friendly finishing agents including citric acid, $\mathrm{TiO}_{2}$ nanoparticles and flame retarding agent based on phosphate salts.

\section{Experimental}

Materials

Mill scoured and bleached plain weave cotton fabric (169 $\left.\mathrm{g} / \mathrm{m}^{2}\right)$ was supplied by Misr Company for Spinning and Weaving), Mehalla Elkobra, Egypt. The fabric was further purified by treatment with a solution containing $2 \mathrm{~g} / \mathrm{l}$ sodium carbonate and $5 \mathrm{~g} / \mathrm{l}$ Egyptol for $2 \mathrm{~h}$. at boiling.

*Corresponding author e-mail: aokeil2004@yahoo.com; phone: +20 2 33335939; fax: +20 233322424 
After that the fabric was washed thoroughly with distilled water and left to dry in open air. Citric acid, titanium tetraisopropoxide, $\mathrm{HCl}$, ethyl alcohol were of laboratory grade chemicals. Flovan CWF (flame retarding agent) was kindly supplied by Huntsman, Germany.

\section{Treatment}

Cotton fabric samples were padded to about $100 \%$ wet pickup with a finishing formulation bath containing 4-8\% citric acid and 2-4\% $\mathrm{TiO}_{2}$ from mother sol solution. Padded fabrics were dried at $100^{\circ} \mathrm{C}$ for $5 \mathrm{~min}$. and cured at a temperature of $120^{\circ} \mathrm{C}$ to $180^{\circ} \mathrm{C}$ for 60 to 180 seconds. Finally, the samples were washed thoroughly with tap water to remove the non-reacted materials.

\section{Preparation of titanium dioxide nanoparticles} (TiO2-NPs)

Titanium tetraisopropoxide $6 \mathrm{ml}$ was mixed with $2 \mathrm{ml}$ of $1 \%$ acetic acid with continuous stirring using magnetic stirrer [16]. After 5 min., $56 \mathrm{ml}$ of ethanol was added drop wise with continuous stirring then $\mathrm{pH}$ of the solution was adjusted to $1-2$ by adding $2 \mathrm{ml}$ of concentrated $\mathrm{HCl}$. The mixture was magnetically stirred well for 45 min., and then obtained the sol-gel $\mathrm{TiO}_{2}$ while was characterized by TEM.

\section{Testing and Analysis \\ Self-cleaning finishes and testing}

The untreated and $\mathrm{TiO}_{2}$-loaded fabric samples were dipped in a basic blue dye solution ( $1 \%$ owf) for $15 \mathrm{~min}$. for staining, then dried and conditioned. The samples were exposed to day light irradiation for $12 \mathrm{hr}$. The color strength, expressed as K/S value, of untreated and $\mathrm{TiO}_{2}$-loaded fabric samples was measured. The decrease in $\mathrm{K} / \mathrm{S}$ values is a direct consequence of the degradation of the dye stains $[17,18]$. It is determined according to the following relation:

Extent of discoloration $(\%)=(\mathrm{K} / \mathrm{S}) \mathrm{a} \times 100 \backslash(\mathrm{K} / \mathrm{S}) \mathrm{b}$ where $(\mathrm{K} / \mathrm{S}) \mathrm{a}$ is the color strength after exposing to daylight and $(\mathrm{K} / \mathrm{S}) \mathrm{b}$ is the color strength before exposing to daylight .

$\mathrm{K} / \mathrm{S}=(1-\mathrm{R}) 2 / 2 \mathrm{R}$, where $\mathrm{K} / \mathrm{S}$ is the ratio of absorption and scattering coefficient and $\mathrm{R}$ is the reflectance at the wave length of maximum absorbance of the used basic dye.

\section{Crease recovery angle (CRA)}

CRA was measured according to the AATCC standard test method "wrinkle recovery of fabrics" (recovery angle method 66-1990).

Tensile strength (TS) and elongation at break (El)

TS and El were measured using the textile tensile Egypt. J. Chem. Special Issue (2017) strength tester (Asano) No. 6202 machine (Japan).

Thermal gravimetric analysis (TGA)

TGA was carried out using Perkin Elmer 7DX Thermo Gravimetric Analyzer, USA.

\section{Scanning electron microscope (SEM)}

The samples were examined by a JEOL840X scanning electron microscope, from Japan, magnification range 35-10,000, resolution $200 \mathrm{~A}^{\circ}$ , acceleration voltage $19 \mathrm{kV}$. All the samples were coated with gold before SEM testing.

Transmission electron microscope (TEM)

TEM was measured using Zeiss-EM10-Germany. $U V$-vis spectrum:

UV-vis spectrum was recorded on Perkin Elmer Lambda 3B UV-Vis spectrometer.

Energy dispersive X-ray (EDX),

The elemental ratio of prepared cotton fabric was characterized by SEM-EDS (electron dispersive spectroscopy) (JXA-840 an Electron Probe Microanalyzer-JOEL).

\section{Results and discussion}

Effect of citric acid concentration

This work is conducted to impart to cotton fabrics multi-functional properties including (flame retardant, self cleaning and anti-crease). To fulfill this target $\mathrm{TiO}_{2}$ nanoparticles, citric acid and Flovan CWF (flame retarding agent) were used. Citric acid was used in the range 0-6\% (owf), $\mathrm{TiO}_{2}$ nanoparticles were used in the range of 2- $4 \%$ (owf) and Flovan CWF was used in the range of $100-400 \mathrm{~g} \backslash 1$. The curing temperature was in the range of $120^{\circ} \mathrm{C}$ to $180^{\circ} \mathrm{C}$ for time ranging from 60 second to 180 second. To reveal the effect of the amount of citric acid on the properties of the treated fabrics the fabrics were treated by formulation consists of $3 \% \mathrm{TiO}_{2}$ nanoparticles with different amount of citric acid ranging from 0 - $6 \%$ padded to $100 \%$ wet pick-up, the samples were dried at $100^{\circ} \mathrm{C}$ for 5 minute and cured at $160^{\circ} \mathrm{C}$ for 3 minute. It is worthy mentioning that sodium hypophosphite was not used as catalyst for crosslinking of cellulosic fabrics with citric acid, aiming to replace it by $\mathrm{TiO}_{2}$ nanoparticles due to the adverse effect of sodium hypophosphite on properties of treated fabrics and environment.

Table 1 shows the results of the effect of citric acid concentration on the CRA, TS, El at break, WI and self cleaning expressed as the extent of discoloration (\%). Table 1 indicates that CRA is elevated by increasing the concentration of citric acid 
from 0 to $6 \%$. The elevation of CRA is expected as the amount of citric acid increases the ability of crosslinking cellulosic chains increases which is true only in case of using a catalyst has the ability to initiate crosslinking through an anhydride formation. In this case the catalyst is $\mathrm{TiO}_{2}$ nanoparticles; this is a quite good proof that $\mathrm{TiO}_{2}$ nanoparticles have the ability to initiate the crosslinking of cellulose by citric acid, so it can be used as a catalyst for crosslinking with citric acid [19].

Table 1 shows also that TS and WI decrease with increasing citric acid concentration; this adverse effect of citric acid on the TS and WI can be attributed to the increasing of the acidity of the medium with increasing citric acid concentration especially at high curing temperature. Self cleaning is the property of the ability of the fabrics to clean itself. This phenomenon is the most characteristic of $\mathrm{TiO}_{2}$, the results of extent of discoloration were found to be about $50 \%$. As mentioned before the self cleaning property is attributed to the presence of $\mathrm{TiO}_{2}$, so as the concentration of $\mathrm{TiO}_{2}$ is fixed the ability of the samples of self cleaning was fixed to about $50 \%$.

Effect of TiO2 nanoparticles concentration
To optimize the quantity of $\mathrm{TiO}_{2}$ nanoparticles needed to impart self cleaning property to cotton fabrics, the concentration of $\mathrm{TiO}_{2}$ nanoparticles must be changed. So the concentration of $\mathrm{TiO}_{2}$ nanoparticles will be used in this section in the range of $2-4 \%$ in presence of $6 \%$ citric acid. The samples will be dried at $100^{\circ} \mathrm{C}$ for $5 \mathrm{~min}$ and cured at $160^{\circ} \mathrm{C}$ for $3 \mathrm{~min}$.

$$
\begin{aligned}
& \mathrm{TiO}_{2}+\mathrm{hv} \rightarrow \mathrm{TiO}_{2}\left(\mathrm{e}^{-}+\mathrm{h}^{+}\right) \\
& \mathrm{H}_{2} \mathrm{O}+\mathrm{TiO}_{2}(\mathrm{~h}+) \rightarrow \mathrm{TiO}_{2}+\cdot \mathrm{OH}+\mathrm{H}^{+} \\
& \mathrm{O}_{2}+\mathrm{TiO}_{2}\left(\mathrm{e}^{-}\right) \rightarrow \mathrm{TiO}_{2}+{ }^{\cdot} 2^{-} \\
& \text {Mechanism of self cleaning of } \mathrm{TiO}_{2}
\end{aligned}
$$

It is obvious that increasing the concentration of $\mathrm{TiO}_{2}$ nanoparticles from 2 to $4 \%$ (Table 2 ) has almost no effect on the self cleaning properties of cotton fabrics expressed as the extent of discoloration of the dyed fabrics. According to the results obtained there is no need to use $\mathrm{TiO}_{2}$ nanoparticles with concentration higher than 2 $\%$. Meanwhile using a higher amount of $\mathrm{TiO}_{2}$ nanoparticles leads almost to the same results with respect to TS, CRA, El and WI. This means that $2 \%$ of $\mathrm{TiO}_{2}$ nanoparticles is almost sufficient to give enough self cleaning and also does not affect

TABLE.1. Effect of citric acid concentration.

\begin{tabular}{|c|c|c|c|c|c|}
\hline $\begin{array}{c}\text { Citric acid } \\
\mathbf{\%}\end{array}$ & $\begin{array}{c}\text { CRA } \\
(\mathbf{W}+\mathbf{F})^{\mathbf{0}}\end{array}$ & $\begin{array}{c}\text { TS } \\
(\mathbf{w . k g})\end{array}$ & EL (\%) & WI & $\begin{array}{c}\text { Extent of discoloration } \\
(\mathbf{\%})\end{array}$ \\
\hline \multirow{2}{*}{ Blank } & 161 & 67 & 18 & 75 & 0 \\
\cline { 2 - 6 } 0 & 168 & 58 & 17.5 & 71.95 & 49 \\
\cline { 2 - 6 } 1 & 171 & 56 & 16 & 72.77 & 50 \\
\cline { 2 - 6 } 2 & 173 & 58 & 16.5 & 72.67 & 48 \\
\cline { 2 - 6 } 4 & 177 & 56 & 15.5 & 70.22 & 49 \\
\cline { 2 - 6 } 6 & 176 & 52.5 & 16.5 & 66.29 & 51 \\
\hline
\end{tabular}

Finishing formulation: Flavon CWF (400 g/L); $\mathrm{TiO}_{2} \mathrm{NPs}_{3} \%$; Wet-pickup (100\%); drying at $100 \circ \mathrm{C} / 5$ min, curing at 160 ${ }^{\circ} \mathrm{C} / 180 \mathrm{sec}$.

TABLE . 2. Effect of $\mathrm{TiO}_{2}$ nanoparticles concentration.

\begin{tabular}{|c|c|c|c|c|c|}
\hline \multirow{2}{*}{$\begin{array}{c}\text { TiO } \\
\text { mother sol-gel }\end{array}$} & $\begin{array}{c}\text { CRA } \\
(\mathbf{W}+\mathbf{F})^{\mathbf{0}}\end{array}$ & $\begin{array}{c}\text { TS } \\
(\mathbf{w . k g})\end{array}$ & El \% & WI & Extent of discoloration (\%) \\
\hline \multirow{2}{*}{3} & 174 & 59 & 18.5 & 72 & 49 \\
\cline { 2 - 6 } & 177 & 59 & 15.5 & 70.2 & 50 \\
\cline { 2 - 6 } 4 & 167 & 56.5 & 15.5 & 70 & 49 \\
\hline
\end{tabular}

Finishing formulation: Flavon CWF (400 g/L); Citric acid $6 \%$; Wet-pickup (100\%); drying at $100{ }^{\circ} \mathrm{C} / 5 \mathrm{~min}$, curing at 160 ${ }^{\circ} \mathrm{C} / 180$ sec. 
adversely the physical and mechanical properties of treated fabrics.

\section{Effect of curing temperature}

Table 3 discloses the effect of curing temperature in the range studied $\left(120^{\circ} \mathrm{C}\right.$ to $\left.180^{\circ} \mathrm{C}\right)$ on the physical and mechanical properties of treated cotton fabrics with $6 \%$ citric acid, $3 \%$ $\mathrm{TiO}_{2}$ nanoparticles, wet pick up $100 \%$ dried at $100^{\circ} \mathrm{C}$ for 5 minute and curried at different curing temperatures. It is shown from the results of Table 3 that crosslinking of cellulosic fabrics is temperature dependent. Increasing curing temperature leads to clear enhancement in the CRA. Higher curing temperatures would act in favors of segmental movement in cotton substrate as well as more ability of the reagents under investigation. This is expected to create accessible environment which help establish interaction of these reagents with the cotton hydroxyls.

This means that increasing curing temperature has an incremental effect on the crosslinking of cellulosic fabrics with citric acid.

Table 3 shows also the effect of curing temperature on the TS and WI which is an adverse effect to the effect on the CRA. A curing temperature of $160{ }^{\circ} \mathrm{C}$ optimum curing temperature which gives an optimal crease recovery angle without adversely affecting the TS and WI. With respect to self cleaning, Table 3 shows the effect of curing temperature on the self cleaning properties of the treated cotton fabrics. Almost curing temperature has no effect on the self cleaning properties since the only source for self cleaning is $\mathrm{TiO}_{2}$ nanoparticles and the concentration of $\mathrm{TiO}_{2}$ is fixed regardless to curing temperature.

\section{Effect of curing time}

As mentioned before curing temperature has the ability to facilitate the movement of the reagents to vicinity of the cellulose functional groups.

Curing time will give these reagents the chance to react with the cellulose molecules, curing time increases the opportunity of increasing the efficiency of reaction increases.

Table 4 depicts that 1.5 minute is enough time to give a valuable CRA without negatively affecting the physical and mechanical properties

TABLE. 3. Effect of curing temperature.

\begin{tabular}{|c|c|c|c|c|c|}
\hline $\begin{array}{c}\text { Curing temperature } \\
(\mathbf{0})\end{array}$ & $\begin{array}{c}\text { CRA } \\
(\mathbf{W}+\mathbf{F})^{\mathbf{0}}\end{array}$ & $\begin{array}{c}\text { TS } \\
(\mathbf{w . k g})\end{array}$ & EI \% & WI & Extent of discoloration(\%) \\
\hline blank & 161 & 67 & 18 & 75 & 0 \\
\hline 120 & 159.5 & 52 & 15 & 69.58 & 50 \\
\hline 140 & 159.5 & 54 & 12 & 69.32 & 49 \\
\hline 160 & 174 & 56 & 18.5 & 70 & 50 \\
\hline 180 & 175 & 20.5 & 12 & 50.75 & 50 \\
\hline
\end{tabular}

Finishing formulation: Flavon CWF $(400 \mathrm{~g} / \mathrm{L})$; Citric acid $6 \% ; 3 \%$ of $\mathrm{TiO}_{2}$, Wet-pickup $(100 \%)$; drying at $100 \circ \mathrm{C} / 5 \mathrm{~min}$.

TABLE. 4. Effect of curing time.

\begin{tabular}{|c|c|c|c|c|c|}
\hline $\begin{array}{c}\text { Curing Time } \\
(\text { min.) }\end{array}$ & $\begin{array}{c}\text { CRA } \\
(\mathbf{W}+\mathbf{F})^{\mathbf{0}}\end{array}$ & $\begin{array}{c}\text { TS } \\
(\mathbf{w . k g})\end{array}$ & El \% & WI & Extent of discoloration \\
\hline 1 & 178 & 46.5 & 11 & 69.58 & 48 \\
\hline 1.5 & 179 & 47.5 & 12 & 69 & 49 \\
\hline 2 & 174.5 & 44 & 10 & 70 & 49 \\
\hline 3 & 182 & 42 & 13 & 63 & 49 \\
\hline
\end{tabular}

Finishing formulation: Flavon CWF (400 g/L); Citric acid $6 \% ; 3 \%$ of TiO2, Wet-pickup (100\%); drying at $100{ }^{\circ} \mathrm{C} / 5$ min., curing at $160^{\circ} \mathrm{C}$.

Egypt. J. Chem. Special Issue (2017) 
of treated fabrics (TS, El and WI). Here too, the results of self cleaning did not change as the amount of $\mathrm{TiO}_{2}$ remained constant regardless of the curing time within the range studied.

Effect of the concentration of Flovan CWF on the properties of cotton fabrics

Table 5 reveals the effect of flame retarding agent on the properties of treated fabrics. It is seen that as the concentration of Flovan CWF increases from 100 to $400 \mathrm{~g} / \mathrm{l}$ at fixed amount of citric acid and $\mathrm{TiO}_{2}$ nanoparticles there is no effect on the physical and mechanical properties of cotton fabrics. Presence of Flovan CWF in the treatment formulations leads to an important effect on the thermal stability of cotton fabric as shown in Fig. 1 (a, b and c). Figure 1 shows the TGA spectra of untreated cotton fabrics, cotton fabrics treated with citric acid and $\mathrm{TiO}_{2}$ nanoparticles and cotton fabrics treated with citric acid and $\mathrm{TiO}_{2}$ in presence of Flovan CWF (flame retarding agent) respectively.

It is clear from Fig. 1 that the maximum decomposition temperature of the cotton fabrics in question are $358^{\circ} \mathrm{C}, 260^{\circ} \mathrm{C}$ and $260^{\circ} \mathrm{C}$ for untreated fabric, treated fabrics with citric acid and $\mathrm{TiO}_{2}$ nanoparticles and cotton fabrics treated with citric acid and $\mathrm{TiO}_{2}$ nanoparticles in presence of Flovan CWF respectively. Figure 1 shows also that the weight loss as are $78 \%, 57 \%$ and $33 \%$ for untreated fabrics, treated fabrics with citric acid and $\mathrm{TiO}_{2}$ nanoparticles and treated fabrics with citric acid and $\mathrm{TiO}_{2}$ nanoparticles in presence of Folvan CWF respectively, which means that presence of Flovan CWF enhances the thermal stability of cotton fabrics.

\section{TEM of TiO2 nanoparticles}

Figure 2 shows TEM of the prepared $\mathrm{TiO}_{2}$ nanoparticles. It is clear that the size and shape of the prepared $\mathrm{TiO}_{2}$ nanoparticles are homogeneous and the nanoparticles size displays a range of 3-7 nm.

\section{Scanning electron microscope (SEM)}

Figure $3(a, b, c)$ reveals the SEM images of untreated fabric, treated fabrics with citric acid in presence of $\mathrm{TiO}_{2}$ nanoparticles and treated samples with citric acid in presence of $\mathrm{TiO}_{2}$ nanoparticles and flame retarding agent (Flovan CWF) respectively. As is evident the Figure exhibits the presence of $\mathrm{TiO}_{2}$ nanoparticles citric acid and Flovan CWF on the surface of treated cotton fabrics.

\section{Energy dispersive X-ray (EDX)}

Figure 4 proofs the presence of $\mathrm{TiO}_{2}$ nanoparticles on the surface of cotton fabrics and the $\%$ of $\mathrm{TiO}_{2}$ on the surface amounts to $0.25 \%$ on the weight of the fabric.

\section{Conclusion}

Cotton fabrics were treated using prepared $\mathrm{TiO}_{2}$ nanoparticles in presence of citric acid and commercially flame retarding agent named Flovan CWF. This was done to produce cotton fabrics having multi-functional properties (anticrease, self cleaning, and flame retardant) through employment of the pad-dry-cure- method. The treated fabrics were submitted to several testing and methods such as creases recovery angle (CRA), Tensile strength (TS), Elongation at break (El), whiteness index (WI), self cleaning and flame retarding properties expressed as thermal gravimetric analysis (TGA). Results obtained make it possible to conclude that $\mathrm{TiO}_{2}$ nanoparticles has a dual effect 1) it is catalyst for crosslinking of cotton fabrics with citric acid 2 ) it is a finishing agent to impart self cleaning properties for cotton fabrics.on the other hand Flovan CWF induces give the ability to cotton fabrics to be flame retardant property to be fabric when used at a concentration of more than 200 $\mathrm{g} / \mathrm{l}$ without seriously affecting the physical and mechanical properties of the cotton fabric.

TABLE 5. Effect of the concentration of Flovan CWF on the properties of cotton fabrics.

\begin{tabular}{|c|c|c|c|c|}
\hline $\begin{array}{c}\text { Flovan CWF } \\
(\mathbf{g} \backslash \mathbf{l})\end{array}$ & $\begin{array}{c}\text { CRA } \\
(\mathbf{W}+\mathbf{F})^{\mathbf{0}}\end{array}$ & $\begin{array}{c}\text { TS } \\
(\mathbf{w . k g})\end{array}$ & El \% & WI \\
\hline 100 & 171 & 53 & 14 & 71.73 \\
\hline 200 & 173 & 56 & 12 & 71.65 \\
\hline 300 & 180 & 56 & 12.5 & 68.85 \\
\hline 400 & 174 & 53 & 13 & 66.21 \\
\hline
\end{tabular}

Finishing formulation: Citric acid $6 \% ; 3 \%$ of TiO2, Wet-pickup (100\%); drying at $100{ }^{\circ} \mathrm{C} / 5 \mathrm{~min}$., curing at $160{ }^{\circ} \mathrm{C}$. 


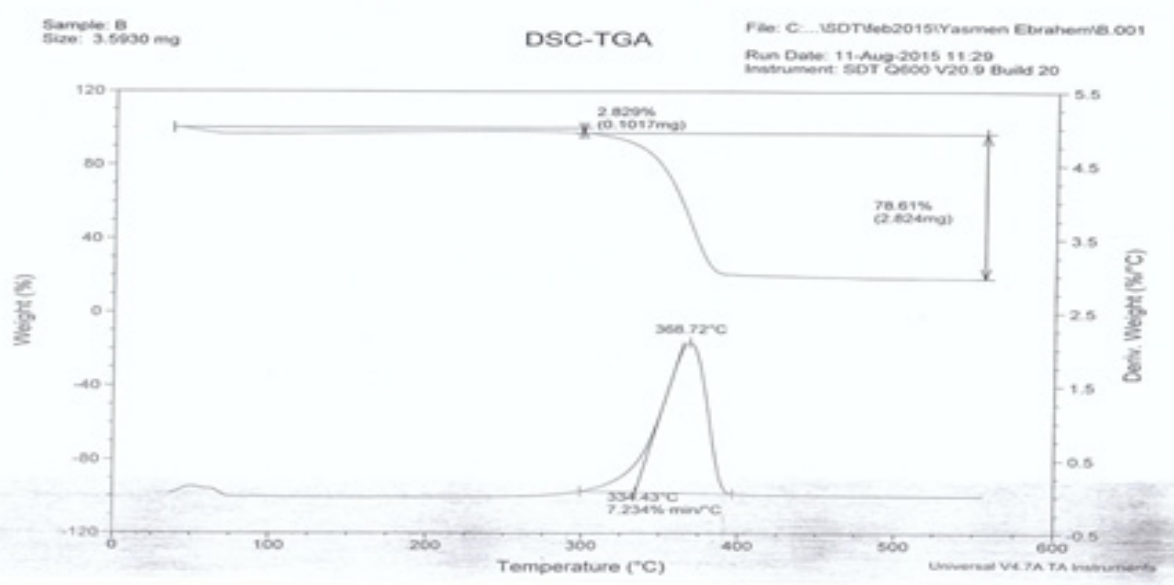

(a)

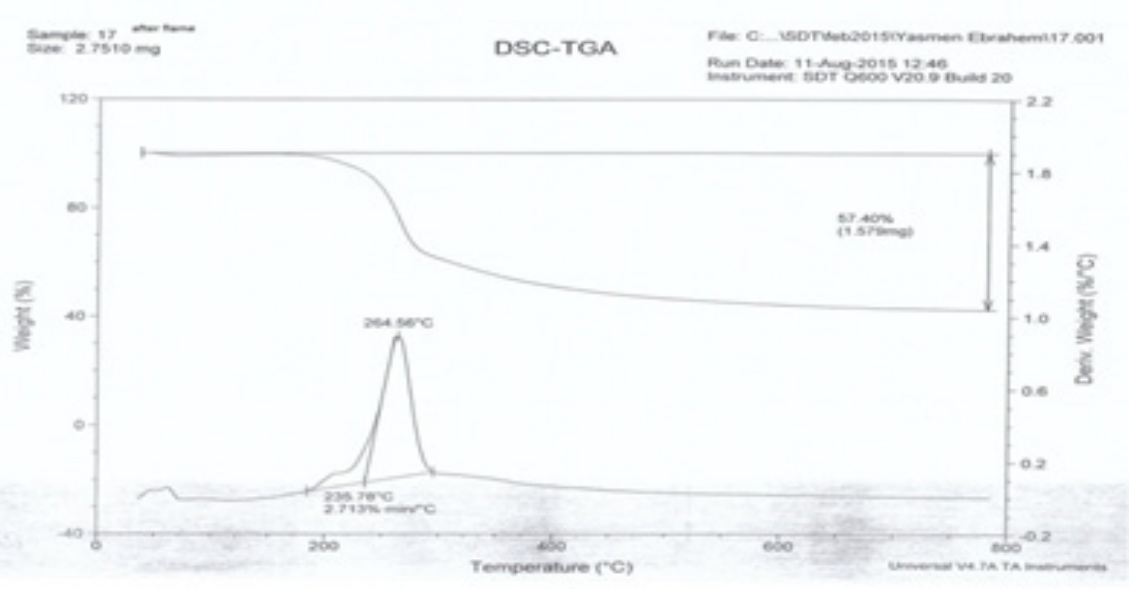

(b)

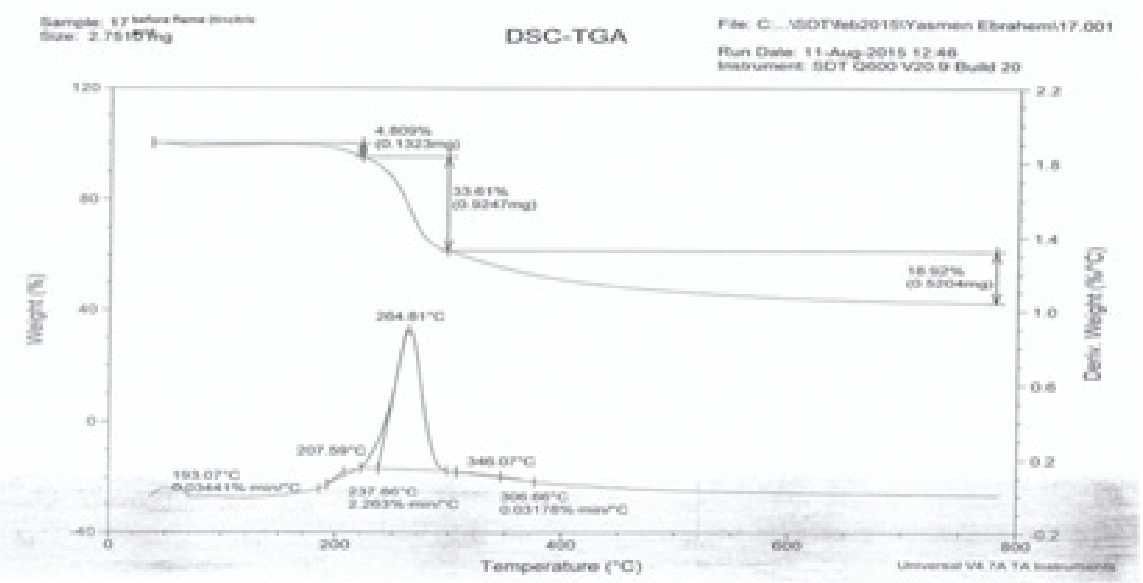

(c)

Fig. 1. TGA of cotton fabrics.

Egypt. J. Chem. Special Issue (2017) 


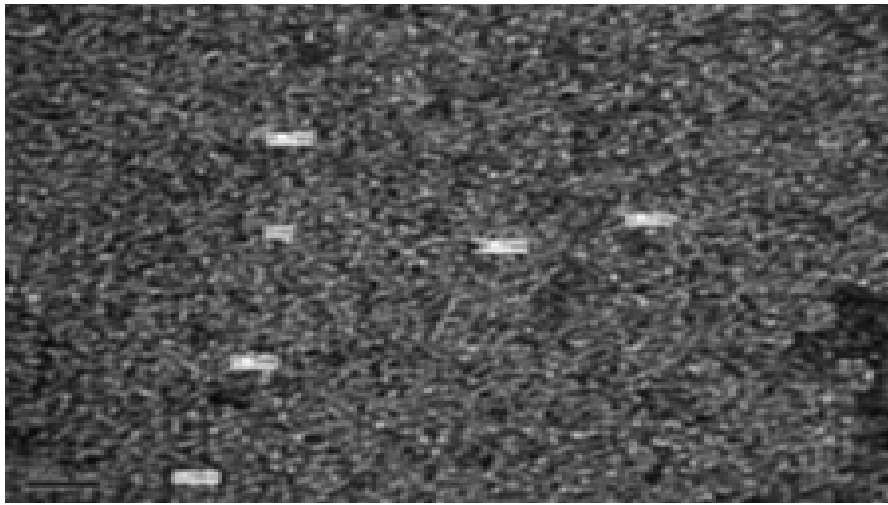

Fig. 2. TEM of $\mathrm{TiO} 2$ nanoparticles

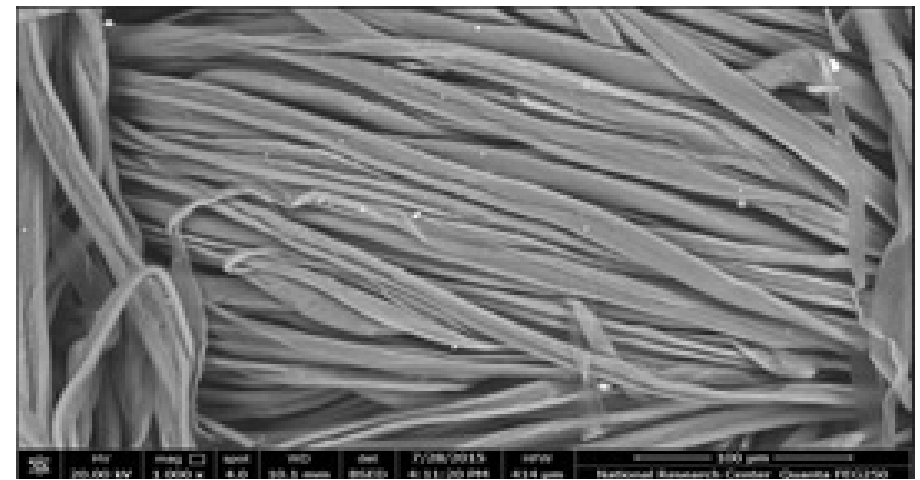

(a)

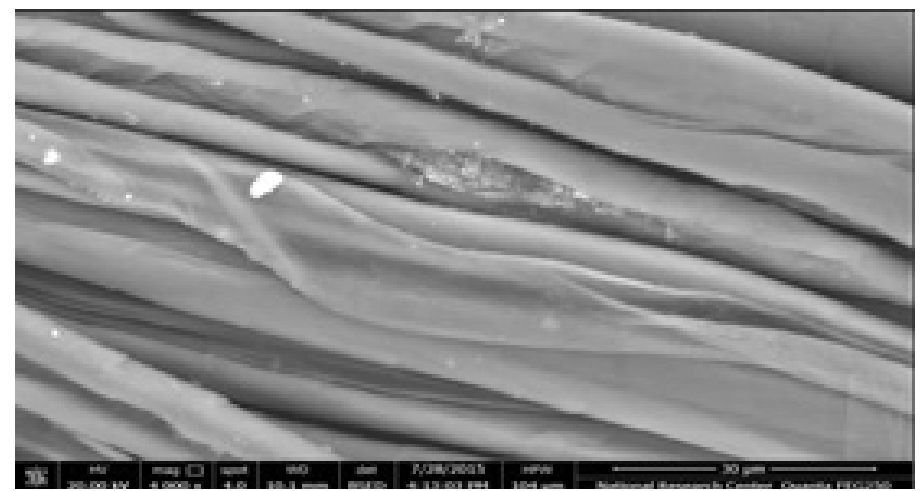

(b)

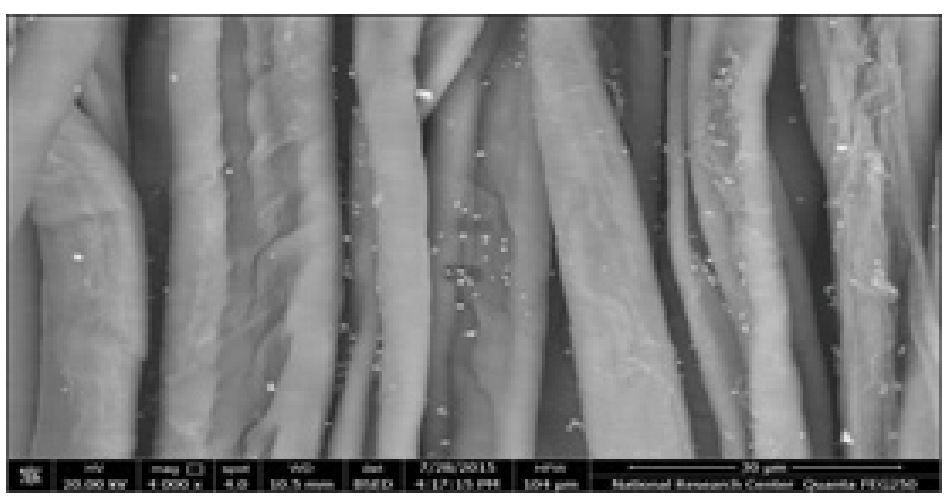

(c)

Fig. 3. SEM Images.

Egypt. J. Chem. Special Issue (2017) 


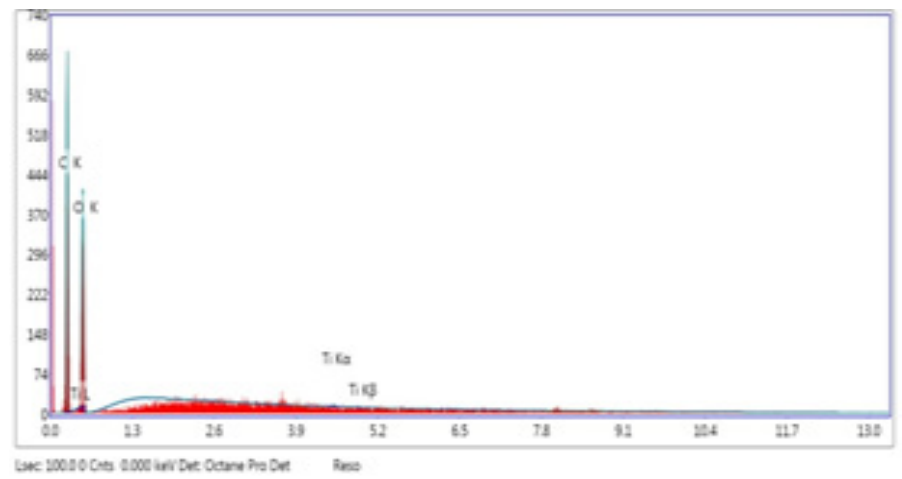

Fig. 4. EDX of treated cotton fabrics.

\section{References}

1. Charuchinda S., Srikulkit, K. and Mowattana T. Co-application of sodium polyphosphate and chitosan to improve flame retardancy of cotton fabric. Journal of Scientific Research, Chulalongkorn University, 30(1), 97-107 (2005).

2. Holme I., FR and the environment. International Dyer, January, 34-37 (2001).

3. Kandola B. K., Horrocks A. R., Price D., and Coleman G. V., Flame retardant treatments of cellulose and their influence on the mechanism of cellulose pyrolysis. Journal of Micromolecular Science, Reviews in Macromolecular Chemistry and Physics, C 36 (4), 721-794 (1996).

4. Abdel-Mohdy F. A., Graft copolymerization of nitrogen and phosphorus containing monomers onto cellulosics for flame retardant finishing of cotton textiles. Journal of Applied Polymer Science, 89, 2573-2578 (2003).

5. Abdel-Mohdy F. A., Khalil E. M., Belyakova M. K., Gaballa M. M. and Yakout E. M., Fire retardant cotton. Journal of Textile Association, 39-44. (2002).

6. Abdel-Mohdy F. A., Belyakova, M. K. and Gaballa, M. M., Studies on some flame retardants for cotton. Colourage, 27-34. (2002).

7. Abou-Okeil A., and El-Shafie A., Urea phosphate/_cyclodextrin inclusion complex to enhance thermal behavior of cotton fabric. Carbohydrate Polymers, 84, 593-598 (2011).

8. Russell E., Nanotechnologies and the shrinking world of textiles, Textile Horizons,. 9/10: p. 7-9.(2002).

9. Cramer, Dean, R., Ponomarenko, Anatolyevna E., Laurent, S.,and Burckett, J.C.T.R., Method of applying nanoparticles, U.S. Pat. No: 6,645,569, (2003).

10. Anonymous, Small-scale technology with the promise of big rewards, Technical Textiles International., 3, p. 13-15. (2003).
11. Xin J.H., Daoud W.A., and Kong Y.Y., A new approach to UV-Blocking Treatment for cotton fabrics, Textile Research Journal,. 74, p. 97-100. (2004).

12. Yeo, S.Y., Lee, H.J., and Jeong, S.H., Preparation of nanocomposite fibers for permanent antibacterial effect, Journal of Materials Science,. 38, 21432147 (2003)

13. Yang H.Y., Zhu S.K. and Pan, N., Studying the mechanisms of titanium dioxide as ultravioletblocking additive for films and fabrics by an improved scheme, Journal of Applied Polymer Science., 92, p. 3201-3210. (2003).

14. Saito M., Antibacterial, deodorizing, and UV absorbing materials obtained with zinc oxide ( $\mathrm{ZnO})$ coated fabrics, Journal of Coated Fabrics., 23, p. 150-164. (1993).

15. Xiong M.N., Gu G.X., You B., and Wu L.M., Preparation and characterization of poly (styrenebutyl acrylate) Latex / Nano- $\mathrm{ZnO}$ nanocomposites, Journal of Applied Polymer Science., 90, p. 1923-1931. (2003)

16. Vives S. and Meunier C., Influence of the synthesis Route on Sol-gel SiO2-TiO2 (1:1) Xerogels and Powders, Ceram. Int. 34, 37-44. (2008)

17. Ibrahim N.A., Amr A., Eid B.M., El-Sayed Z.M. and Fahmy H.M., Poly (acrylic acid)/Poly(ethylene glycol) adduct for attaining multifunctional cellulosic fabric, Carbohydrate Polymers, 89, (2), 648-660. (2012).

18. Bozzi A., Yuranova T., Guasaquillo I., Laub D. and Kiwi J., Self-cleaning of modified cotton textiles by $\mathrm{TiO} 2$ at low temperatures under daylight irradiation, Journal of Photochemistry and Photobiology, A: Chemistry, 174, 156-164. (2005).

19. Abou Okeil, Citric acid crosslinking of cellulose using $\mathrm{TiO}_{2}$ catalyst by pad-dry-cure method, polymer-plastics. Technology and Engineering, 47, 174-179, (2008).

(Received 31/12/2017; accepted 22/2/2018)

Egypt. J. Chem. Special Issue (2017) 


\title{
التجهيز الوظيفي للاقمشة القطنية باستخدام تكنولوجيا النانو ومواد تجهيز صديقة للبيئه
}

\author{
اشرف ابو عقيل'، رشدي عيد'، احمد عمرو'

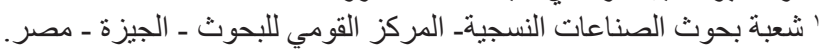

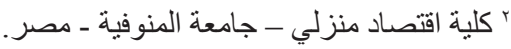

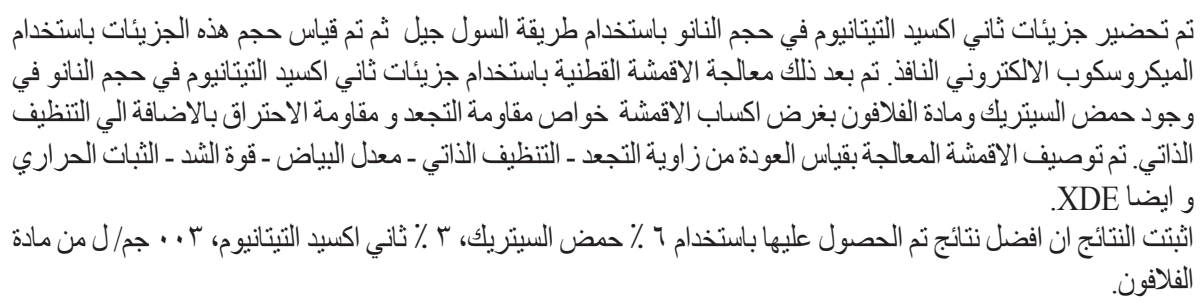

Egypt. J. Chem. Special Issue (2017) 